\title{
Desafios da implementação de uma política intersetorial e federativa: as burocracias de médio escalão do Programa Bolsa Família
}

\author{
Vanessa Elias de Oliveira \\ Universidade Federal do $A B C$ (UFABC)
}

Gabriela Spanghero Lotta

Fundação Getulio Vargas (FGV)

Matheus Nunes

Bacharel em Políticas Públicas e Ciências e Humanidades pela Universidade Federal do $A B C$ (UFABC)

O artigo discute o processo de implementação de uma política pública intersetorial e que demanda coordenação federativa, o Programa Bolsa Família (PBF), a partir da perspectiva da burocracia de médio escalão. Políticas com tais características enfrentam um grande desafio para sua gestão, que é a conexão das distintas burocracias públicas, tanto de diferentes setores quanto de diferentes níveis de governo. Para compreender como as burocracias de médio escalão percebem os desafios da implementação de uma política com tais características, a pesquisa analisou, por meio de pesquisa qualitativa (entrevistas), parte da burocracia de diferentes níveis de governo (municípios, estados e União) envolvida com a implementação do PBF. Discutindo com a literatura sobre implementação de políticas públicas, intersetorialidade, relações federativas e burocracia de médio escalão, demonstramos que, para além das desigualdades locais e das distintas capacidades burocráticas dos níveis de governo, os gestores federais e municipais percebem como um exercício constante a construção da intersetorialidade na operação do programa e, ainda, entendem que o Governo Federal deveria desenvolver mecanismos para a compreensão do que acontece "na ponta", nos processos municipais de implementação, incorporando esses aprendizados ao (re)desenho da política, adequando-a às distintas realidades locais.

Palavras-chave: burocracia de médio escalão, implementação, Programa Bolsa Família, federalismo, política intersetorial.

[Artigo recebido em 15 de maio de 2018. Aprovado em 28 de junho de 2019.] 
Challenges of implementation of an intersectorial and federative policy: The Bolsa Família Program in the view of its bureaucracy

The paper discusses the implementation process of a policy both intersectoral and that requires federal coordination, the Bolsa Família Program (PBF), from the perspective of the middle-level bureaucrats. Policies with such characteristics face a great challenge for their management, which is the connection of different public bureaucrats, from different sectors as well as from different government levels. In order to understand how these bureaucrats perceive the challenges of implementing a policy with such characteristics, the research analyzed, through qualitative research (interviews), the middle-level bureaucrats of different levels of government (municipalities, states and the Union) involved with the PBF implementation. We demonstrate that, in addition to local inequalities and different bureaucratic capacities, federal and municipal managers perceive the construction of intersectoriality as a constant exercise during the program operation. They also understand that the Federal Government should develop mechanisms for understanding what happens "on the ground", in municipal implementation processes, incorporating these learnings into the (re) design of policy, adapting it to the different local realities.

Keywords: bureaucracy, implementation, Bolsa Família Program, federalism, intersectoriality.

\section{Desafíos de la implementación de una política intersectorial y federativa: el programa Bolsa Familia en la perspectiva de los burócratas.}

Elartículo analiza el proceso de implementación de una política pública intersectorial yqué exige coordinación federal - el Programa Bolsa Familia (PBF) - desde la perspectiva de la burocracia de nivel medio. Las políticas con tales características enfrentan un gran desafío por su gestión: la conexión de las diferentes burocracias públicas, tanto de diferentes sectores como de diferentes niveles de gobierno. Para entender cómo las burocracias de nivel medio dan cuenta de los desafíos de implementar una política de este tipo, el artículo analizada, a través de investigación cualitativa (entrevistas), parte de la burocracia de diferentes niveles de gobierno (municipios, estados y la Unión) involucrados en la implementación del PBF. Discutiendo con la literatura sobre la implementación de políticas públicas, intersectorialidad, relaciones federativas y burocracia de nivel medio, demostramos que, más allá de las desigualdades locales y las distintas capacidades burocráticas de los administradores gubernamentales, federales y municipales, los gestores realizan un ejercicio constante para construcción de intersectorialidad en la operación del programa. El gobierno federal debe desarrollar mecanismos para comprender lo que sucede "en procesos de implementación municipal, incorporando estos aprendizajes en el (re) diseño de la política, adaptándola a las diferentes realidades locales.

Palabras-clave: burocracia de nível medio, implementación, Programa Bolsa Familia, federalismo, política intersectorial 


\section{Introdução}

Políticas públicas que são intersetoriais e demandam coordenação federativa enfrentam um grande desafio para sua gestão, que é a conexão das distintas burocracias públicas por elas responsáveis, tanto dos diferentes setores quanto dos diferentes níveis de governo. Cada setor de política pública tem seus interesses e preferências, assim como cada instituição apresenta sua própria cultura organizacional e lógica de atuação. Em termos federativos, as relações intergovernamentais necessárias à implementação das políticas públicas compelem as burocracias à interação, diretamente influenciadas pelo jogo político federativo, com implicações para a sua gestão.

Nesse contexto, as competências necessárias, bem como as possibilidades de interação entre as burocracias implementadoras de políticas intersetoriais e federativas são elementos centrais para o sucesso das mesmas. Com vistas a compreender como as burocracias públicas de médio escalão percebem os desafios da implementação de uma política com tais características, a presente pesquisa analisou parte da burocracia de médio escalão dos diferentes níveis de governo (municípios, estados e União) envolvida com a implementação do Programa Bolsa Família (PBF). A análise da percepção dos burocratas é inspirada numa abordagem interpretativa de análise de políticas públicas que considera que os diferentes atores interpretam as políticas e os contextos de formas distintas e que essa variedade de interpretações interfere no comportamento e nas ações dos atores (PüLZL; TREIB, 2007; YANOW, 1993). Analisar como os burocratas percebem as políticas, seus desafios e suas ações é uma forma de compreender como e por que se comportam como o fazem. Além disso, consideramos que os diferentes estratos burocráticos podem ter percepções distintas sobre as políticas, na medida em que vivenciam relações e desafios diferentes (PIRES; LOTTA; OLIVEIRA, 2018). Assim, compreender como a burocracia de médio escalão percebe os desafios de implementação de uma política pública pode trazer referências importantes tanto para compreender a política como para compreender a própria burocracia.

Com relação ao programa, sua escolha se deu em função de ser este um programa federal que conta com uma burocracia qualificada tecnicamente, conforme já discutido por Silva (2013), que é reconhecidamente exitoso, do ponto de vista da gestão, apesar de ser uma política que soma as duas variáveis acima mencionadas (interação intergovernamental e intersetorialidade) - e que, portanto, contribuiriam para o seu "esperado insucesso".

Para cumprir essa tarefa, o artigo divide-se em quatro partes, incluída a presente Introdução. Em primeiro lugar, apresentamos o referencial teórico que norteou a 
análise dos casos estudados, voltado para a compreensão da chamada "burocracia de médio escalão" e para as capacidades da burocracia para a implementação de políticas públicas intersetoriais e federativas. Nesta também apresentamos de maneira breve o Programa Bolsa Família. Em seguida, detalhamos a metodologia para a seleção dos casos e para a análise dos dados coletados empiricamente, por meio de pesquisa qualitativa baseada em entrevistas semiestruturadas ${ }^{1}$. Por fim, a partir desses resultados, apresentamos as principais conclusões acerca da percepção dos burocratas implementadores do Programa Bolsa Família acerca de políticas públicas intersetoriais e federativas, apontando aspectos que merecem ser considerados não apenas nas análises de políticas com tais características como, mormente, nos processos de implementação e gestão das mesmas.

\section{O Programa Bolsa Família, sua burocracia e os desafios de implementação}

Nos últimos anos, a literatura tem buscado aprofundar a compreensão da atuação da burocracia e seu papel na efetivação das políticas públicas. Foram feitos significativos avanços em termos de compreender a burocracia do alto escalão e a burocracia implementadora (burocracia de nível de rua). Já a burocracia intermediária, aquela que atua no médio escalão, começou a ser estudada mais recentemente (LOTTA; PIRES; OLIVEIRA, 2014). A importância dessa burocracia intermediária está justamente em ser o elo entre o alto escalão e os implementadores das políticas - sendo ela quem conecta a ideia de tomada de decisão (formulação) com a execução. Como apontam Lotta, Pires e Oliveira (2014), a partir dos trabalhos de Huising e Silbey (2011), essa burocracia intermediária tem um papel fundamental no sentido de articulação e promoção de relações entre diferentes tipos de atores:

São os atores responsáveis por interagirem com seus subordinados e garantir deles complacência para implementação das regras desenhadas por níveis superiores. Para as autoras, o papel destes gestores é de governar o gap existente entre as regras e a possibilidade real de aplicação, o que chamam de regular as relações (LOTTA; PIRES; OLIVEIRA, 2014, p.481) .

Em pesquisa recente sobre a atuação, perfil e trajetória da burocracia de médio escalão do Governo Federal, foi reforçada a ideia de que esses atores são estratégicos para efetivação das políticas públicas, na medida em que atuam tanto numa articulação vertical (com superiores e subordinados) como horizontal (com atores de outros setores) (OLIVEIRA; LOTTA, 2014; PIRES, 2015 ABERS, 2015; GODINHO, 2015; SILVA, 2015 ). E é essa atuação articuladora que Ihes permite construir e

\footnotetext{
${ }^{1}$ As entrevistas foram realizadas entre novembro de 2014 e julho de 2015.
} 
implementar políticas que deem conta desse contexto em que os novos arranjos institucionais operam.

No entanto, pouco se sabe sobre as burocracias dos níveis estadual e municipal, que operam nas mesmas políticas públicas, visto que a literatura, na maioria das vezes, concentra-se em estudos da burocracia federal (GouVÊA, 1994; SCHNEIDER, 1994 ; LoUREIRo; Abrucio; RosA, 1998; LOUREIRO; Abrucio, 1999; BRESSER-PEREIRA, 2007; OLIVIERI, 2007), conforme já explicitaram Oliveira e Abrucio (2018).

O escasso conhecimento acerca de quem são e o que fazem os gestores estaduais e municipais acaba sendo, para além de uma lacuna teórica, um desafio para a própria estruturação de políticas com lógica federativa, na medida em que a burocracia federal muitas vezes não encontra nos níveis subnacionais o respaldo necessário para a implementação das políticas públicas desenhadas centralmente, reforçando no discurso e na prática a necessidade de uma lógica centralizadora das políticas, conforme se verificou na Federação brasileira nos últimos anos (ALMEIDA, 2005; ARRETCHE, 2012; OliVEIRA; LOTTA, 2014).

Para compreender o perfil e atuação da burocracia de médio escalão atuante no Programa Bolsa Família e inserida em diferentes contextos institucionais, como municípios e governos estaduais de portes distintos, levantamos a literatura que trata da burocracia inserida no Bolsa Família. Embora ainda bastante escassa, essa literatura aponta para a importância de se compreenderem as relações verticais e horizontais da burocracia, dado que os principais desafios inerentes ao programa estão relacionados à capacidade de coordenar diferentes organizações inter e intragovernamentais em prol da atuação integrada. Em seguida, discutimos os desafios apontados a respeito da articulação horizontal (intersetorialidade), os desafios da articulação vertical (relações federativas), a ideia de capacidades estatais e, por fim, algumas questões sobre competências requeridas aos burocratas para efetivação do programa nesse contexto.

\subsection{O Programa Bolsa Família}

O PBF é um programa de transferência de renda condicionada criado em 2003, num contexto de políticas de combate à pobreza. Como aponta Oliveira (2014), o PBF foi criado com a

missão de unificar os programas nacionais de transferência de renda existentes (Bolsa Escola Federal, Bolsa Alimentação, Auxílio Gás, Cartão Alimentação e Programa de Erradicação do Trabalho Infantil). Ao direcionar recursos para a população em situação de pobreza/pobreza extrema, o PBF incorpora, na sua arquitetura, um conjunto de condições que devem ser satisfeitas pelas famílias beneficiadas, vinculando-as ao programa (OLIVEIRA, 2014, p. 3). 
O Programa Bolsa Família tem três eixos: transferência de renda; condicionalidades (saúde, educação e assistência social); e ações complementares para desenvolvimento das famílias. Para sua estruturação, o PBF conta com a atuação conjunta de diferentes organizações. O Ministério do Desenvolvimento Social (MDS) é o gestor do programa, via Secretaria Nacional de Renda e Cidadania (Senarc). O órgão é responsável por elaborar as normativas, gerenciar o cadastro único e coordenar os demais órgãos envolvidos em torno da ação.

Ainda em nível federal, estão envolvidos o Ministério da Educação e o Ministério da Saúde, responsáveis pela gestão das condicionalidades. A Caixa Econômica Federal também tem papel central, na medida em que é responsável pelo pagamento dos benefícios. Para a implementação do PBF, são também envolvidos governos estaduais e municipais. Os estados deveriam atuar na capacitação e apoio aos municípios, embora nem todos eles executem esse papel. Já aos municípios cabem as principais atividades de implementação do programa, desde realizar o cadastro das famílias beneficiárias até monitorar as condicionalidades. Para tanto, a implementação do PBF nos municípios também pressupõe uma ação articulada de diferentes secretarias. Em geral, a de assistência social, saúde e educação, embora isso possa depender do desenho do programa e da estrutura organizacional em cada localidade.

Em seus mais de 10 anos de existência, o PBF já é identificado como uma política com alto grau de efetividade e inovação. Com relação à inovação, a literatura aponta os vários instrumentos gerenciais com os quais o PBF trabalha como inovadores para garantir a efetivação de um programa com tal grau de coordenação, descentralização e capilaridade (COUTINHO, 2013).

Entre as inovações relatadas estão:

1) Cadúnico e mecanismo de focalização: o Cadúnico é o instrumento de cadastro das famílias beneficiárias do programa, realizado pelos municípios, e é a partir deles que as famílias, enquadradas no perfil exigido, passam a receber as transferências de renda. Atualmente ele tem sido também usado como base informacional para desenho de diversos outros programas do Governo Federal, tendo se transformado num importante instrumento para identificação de famílias de baixa renda e com perfis específicos para se tornarem beneficiários de diversos programas de combate à pobreza (DIREITo et al., 2016). A partir dele o PBF tem conseguido sucesso em termos de focalização da política, já que a margem de erro dos beneficiários é bastante reduzida, o que significa que os recursos alcançam os extratos mais pobres da sociedade a custos relativamente baixos (COUTINHO, 2013; BICHIR, 2011). 
2) Condicionalidades: para receberem a transferência mensal, as famílias precisam atender a uma série de condicionalidades na saúde e na educação. Quanto à saúde, as crianças precisam estar vacinadas, com acompanhamento periódico, bem como as gestantes precisam realizar o pré-natal. Com relação à educação, as condicionalidades dizem respeito à frequência escolar. Elas são apontadas pela literatura como uma importante inovação, que não tem uma lógica punitiva, mas serve como um alerta à vulnerabilidade das famílias (COUTINHO, 2013).

3) IGD: o Índice de Gestão Descentralizada foi criado para avaliar qualidade e atualização das informações do Cadúnico e

assiduidade e a integridade das informações sobre o cumprimento das condicionalidades das áreas de educação e saúde por parte das famílias beneficiárias. Seu objetivo é avaliar mensalmente a qualidade da gestão do PBF e do Cadúnico em cada município e, a partir dos resultados identificados, oferecer apoio financeiro para que os municípios melhorem sua respectiva gestão (COUTINHO, 2013, p. 25).

Ele é apontado pela literatura como um importante instrumento de coordenação federal, na medida em que regula o repasse de recursos entre Governo Federal e municípios (BICHIR, 2011) e permite o monitoramento das ações para promoção de melhorias das capacidades municipais (OLIVEIRA, 2014).

Como se pode perceber, as principais inovações relativas à gestão do PBF dizem respeito à sua capacidade de ampliar os processos de coordenação verticais e horizontais com vistas a garantir a efetivação de um programa com características intersetoriais e federativas. Essa lógica está inserida no contexto dos novos arranjos institucionais, apontados na introdução, que permitem a construção de políticas mais complexas tanto em termos do seu desenho como da sua implementação. Embora esses novos arranjos institucionais marquem uma nova fase para as políticas públicas, certamente aumentando sua capacidade de gerar respostas efetivas, a literatura demonstra que eles também trazem uma série de novos desafios ao Estado em termos de coordenação. Parte desses desafios serão tratados nas duas próximas sessões.

\subsection{Desafios da articulação horizontal - intersetorialidade}

Um primeiro desafio colocado pelo PBF, dada a própria natureza do programa, diz respeito à atuação horizontal - ou intersetorial - para implementação do programa. A intersetorialidade é a coordenação de diferentes setores para, conjuntamente, construírem soluções que resolvam de forma produtiva problemas sociais (CUNIL GRAU, 2005). Ela nasce como resposta ao problema da excessiva especialização 
organizacional que se construiu em organizações ao longo do século 20 e seria, portanto, o ajuste mútuo entre atores ou a adoção de interações mais deliberativas que produziriam resultados positivos aos participantes limitando consequências negativase, ao mesmo tempo, produzindo maior coerência, reduzindo redundâncias, lacunas e contradições entre politicas e dentro delas (BOUCKAERT et al., 2010).

A lógica intersetorial pressupõe articulação e junção de diferentes ações com um foco específico, seja um território onde se quer atuar, um determinado público ou um problema complexo a enfrentar (INOJOSA, 1998). A literatura tem apontado como desafios para implementar políticas relacionados tanto questões estruturais da administração pública como questões relacionadas à cultura das organizações, conhecimentos e crenças das burocracias envolvidas nas políticas.

No caso do PBF, a intersetorialidade se faz na implementação e no monitoramento. A construção de uma política baseada em condicionalidades intersetoriais já traz consigo a necessidade de uma articulação entre diferentes áreas - neste caso, saúde e educação -, que se efetiva com o monitoramento na ponta baseado também na ação conjunta de diferentes áreas.

Bichir (2011) identifica que a coordenação intersetorial tem sido promovida, em grande medida, pela existência dos instrumentos inovadores como o Cadúnico, o IGD e a gestão das condicionalidades, mecanismos pelos quais se integram as ações entre diferentes áreas do Governo Federal e dos municípios.

No entanto, para além dos instrumentos formais, Silva (2013) identifica no Governo Federal um conjunto de outros mecanismos que permitiram a construção de processos coordenados de intersetorialidade:

1) a construção de capacidades técnicas, através da formação de órgãos e de suas burocracias;

2) o empoderamento e a autonomia para experimentação, o que gera condições para que as equipes se engajem fortemente e inovem;

3) a estratégia de utilização das redes informais e das experiências pregressas dos burocratas como instrumentos de incremento e de maior materialização da coordenação;

4) o processo de legitimação técnica e política, tanto pelas relações interpessoais, quanto pelos resultados apresentados pelas burocracias;

5) o processo de fortalecimento institucional e formalização de padrões, em que as contribuições pontuais se unificam e ganham permanência no tempo, moldando e dando estabilidade às instituições (SILVA, 2013, p. 344).

Esses achados, quanto ao Governo Federal, corroboram o que a literatura argumenta sobre o funcionamento de políticas intersetoriais que dependem de 
instrumentos (PIRES, 2015) e da articulação relacional da burocracia (ANDRADE, 2018 ; SILVA, 2013).

No caso dos governos municipais, a necessidade de articulação entre as diferentes secretarias também é um desafio à coordenação intersetorial. No entanto, como aponta Coutinho (2013), para além do desafio de integrar com saúde e educação, nos municípios o PBF tem um enorme desafio em integrar suas ações às ações relacionadas ao Sistema Único de Assistência Social (Suas), o qual diz respeito não apenas a pensar formas conjuntas de cadastrar as famílias e acompanhá-las, mas também a como dispor da mesma burocracia para ações distintas e complementares, como usar as mesmas estruturas físicas, gerenciais e tecnológicas, como potencializar programas municipais complementares e como se utilizar dos mesmos mecanismos de participação social para as diversas ações (COUTINHO, 2013). Isso depende de uma burocracia com habilidades de negociação e articulação com diferentes áreas.

Assim, com relação especificamente à burocracia que gerencia o programa, a intersetorialidade traz um conjunto de desafios na medida em que pressupõe a capacidade desses atores de construírem diálogos com burocracias com diferentes referenciais, lógicas e modus operandi. Isso significa, na prática do PBF, que as burocracias da assistência social precisam dialogar com as da saúde e da educação, ao menos. Esta não tem sido a forma tradicional das burocracias municipais atuarem, principalmente pela falta de carreiras transversais e que circulem entre diferentes áreas. Assim, nos municípios, a articulação acaba dependendo muito mais da capacidade relacional da burocracia especificamente do que de uma estrutura de atores que viabilize essas articulações (ANDRADE, 2018 ).

No caso da burocracia federal, além das articulações com educação e saúde, ainda deve ser feita articulação com os gestores da Caixa Econômica, além daquela dos órgãos de controle. Ademais, dada sua ampla visibilidade, os gestores do PBF também precisam, cada vez mais, se articular com gestores de outros ministérios e setores que buscam construir ações conjuntas com o PBF (OLIVEIRA; LOTTA, 2015). Essa necessidade de atuação com distintos setores exige, por parte dos gestores, amplas capacidades de diálogo, de compreensão de lógicas diferentes, de negociação e de construção de ações integradas, elementos que não estavam presentes nas formas tradicionais de construção de políticas públicas e que, portanto, requerem o desenvolvimento de novas competências na burocracia. Ao mesmo tempo, como mostram pesquisas anteriores (OLIVEIRA; LOTTA, 2015; SILVA, 2013), boa parte da burocracia de médio escalão do MDS é ocupada por gestores concursados em carreiras de Estado - como a de Especialista em Políticas Públicas e Gestão Governamental e a de Analista Técnico de Políticas Sociais. As duas 
carreiras têm como característica a circulação entre diferentes áreas e ministérios, o que potencializa conhecimentos mais intersetoriais e a construção de redes interministeriais.

\subsection{Desafios da articulação vertical - relações federativas}

Um segundo vetor importante na construção do PBF tem a ver com a coordenação federativa, ou seja, com a relação construída entre diferentes entes federativos para a efetivação do programa. Esse elemento é uma das características fundamentais dos novos arranjos institucionais (LOTTA; FAVARETO, 2016 ) que exigem uma compreensão dos processos de coordenação vertical entre diferentes níveis governamentais.

Analisando o caso brasileiro, Arretche (2012) aponta que a Constituição Federal de 1988 descentralizou a execução de uma série de políticas públicas para estados e municípios. No entanto, a descentralização não levou a uma efetiva autonomia dos entes subnacionais em relação às políticas públicas, na medida em que a Constituição (CF) também desenhou regras que deram ampla autoridade legislativa e financeira à União, que acaba exercendo

poderosa influência sobre a agenda e as políticas dos governos subnacionais. Além da legislação aprovada no parlamento, esse poder também é exercido no campo da legislação específica de cada política pública, bem como dos poderes de gasto e supervisão do governo federal (ARRETCHE, 2012, p. 19).

A autora conclui ainda que, no caso brasileiro, há mecanismos institucionais que limitam a autonomia dos governos locais para tomarem decisões sobre suas atividades, mesmo que estes tenham ainda autonomia política. Esse argumento é comprovado por Arretche (2012) demonstrando como diversas políticas sociais são implementadas com lógicas de regulação e repasses de recursos federais, garantindo a elas um grau de padronização mesmo em municípios com partidos e programas políticos distintos.

Para compreender a coordenação federativa no caso do Bolsa Família, a primeira questão é analisar o que diz a CF a esse respeito, considerando as competências ali definidas. Sobre isso, Lício et al. (2011) argumentam que, embora o artigo 23 da Constituição afirme que o combate à pobreza e a integração social sejam responsabilidade comum dos três entes federativos, a CF não estabelece procedimentos para a ação conjunta, o que deixa um desafio às políticas públicas para construção e negociação permanentes em torno de ações articuladas. 
Com relação especificamente ao PBF, Bichir (2011) argumenta que:

No caso do PBF, apesar da descentralização da implementação e da entrega do benefício, a cargo dos municípios, as decisões gerais - inclusive a seleção efetiva dos beneficiários - são centralizadas no nível federal. Nesse sentido, cabe testar a hipótese de que, a despeito da fragmentação inicial dos programas - não só aqueles do nível local, mas mesmo no caso do primeiro programa nacional, o Bolsa Escola -, foi sendo desenvolvido um alto poder regulatório do governo federal sobre as ações municipais, como observado no caso das políticas de educação e saúde. Esse poder regulatório do governo federal se expressa tanto nas regras que regem o cadastramento dos beneficiários do PBF quando nas regras de repasse de recursos federais para estados e municípios (BICHIR, 2011, p. 43).

O PBF estaria, assim, construído numa lógica de coordenação em que o Governo Federal tem responsabilidade sobre definições formais, financiamento e coordenação do programa, enquanto os municípios são os principais responsáveis pela implementação.

A esse respeito, no entanto, Cavalcante (2009) argumenta que o PBF tem como um de seus princípios basilares a ideia de descentralização. Isso se concretizou, segundo o autor, com as medidas empreendidas pelo MDS para fortalecimento da gestão com os municípios, como a ideia de incentivos baseada no apoio técnico e financeiro. Para o autor, esse princípio tem tido resultados positivos "principalmente no que tange ao Cadastro Único, as condicionalidades e gestão de benefícios" (CAVAlCANTE, 2009, p. 22).

Ainda a esse respeito, Lício et al. (2011) afirmam que nos últimos anos tem havido avanços em termos da construção conjunta do programa entre o Governo Federal e os municípios - embora o mesmo não possa ser dito a respeito dos governos estaduais. No entanto, analisando-se os mecanismos de articulação, apontam que eles têm caminhado para:

um padrão mais hierarquizado de relações intergovernamentais na dimensão da transferência de renda, argumento que pode ser evidenciado pelas dezenas de portarias e instruções operacionais relativas à gestão do PBF, publicadas pelo MDS sem negociação prévia com os entes federados (LıCıO et al., 2011, p. 466).

Esse padrão, no entanto, é diferente quando se analisam as condicionalidades. Nesse caso, a atuação dos municípios ganha relevância, dado que as ações para monitoramento das condicionalidades dependem das formas de atuação específicas 
das áreas de políticas públicas nos municípios. Os autores identificam ainda alguns desafios centrais para aprimoramento da coordenação no PBF, que são:

A primeira é relativa ao maior investimento em espaços e oportunidades de negociação nas relações intergovernamentais em todas as suas dimensões, enquanto a segunda relaciona-se com a necessidade de maior coordenação federativa da articulação de programas complementares (LıCıO et al., 2011, p. 468).

O enfrentamento desses desafios passa, necessariamente, pela atuação da burocracia nos três diferentes níveis federativos. Para além da construção de espaços e mecanismos institucionalizados de articulação, demanda-se que a burocracia seja capaz de realizar essas articulações e negociações em torno dos objetivos comuns do programa. Dessa forma, o desafio da articulação vertical se torna um desafio também em termos de competências requeridas aos gestores do programa, tanto no Governo Federal como nos estados e municípios.

\section{Análise dos casos}

Para compreender a percepção da burocracia implementadora do PBF dos três níveis governamentais sobre a gestão do programa foram contemplados municípios de diferentes portes (pequeno, médio e grande), de forma que fossem investigadas uma diversidade de situações e realidades. Nesta seção, apresentaremos a metodologia para seleção de municípios realizada para pesquisa de campo. Em seguida, analisamos as entrevistas e principais achados da pesquisa empírica.

\subsection{Seleção de municípios e seus atores}

Optou-se por escolher municípios de um mesmo estado, no caso o Estado de São Paulo. Essa seleção se deu por ser São Paulo o estado com o segundo maior número de beneficiários do PBF, perdendo apenas para a Bahia², apesar de ser o estado mais rico da Federação, com uma burocracia forte e bastante estruturada. Ademais, ao contrário da Bahia, que contou com o governo estadual do PT desde 2007, alinhado ao Governo Federal, o governo do Estado de São Paulo está nas mãos do PSDB desde antes da criação do programa, colocando mais um desafio ao seu processo de implementação - a interlocução política para a viabilização subnacional da política federal. Esses elementos tornam o Estado de São Paulo um caso interessante para se estudar o papel da burocracia na implementação do programa. Neste, selecionamos a região metropolitana de São Paulo, que conta

\footnotetext{
${ }^{2}$ Dados obtidos em https://aplicacoes.mds.gov.br/sagi/vis/data/data-table.php. Acessado em 02/12/2018.
} 
com municípios de diferentes portes (39 ao todo). Foram adotados como critérios de seleção: porte do município; taxa de acompanhamento das condicionalidades e cobertura (alta ou baixa); valor de recursos IGD-PBF; variação no número de famílias atendidas. Foram definidos os seguintes municípios: Embu-Guaçu, Caieiras, BiritibaMirim e Vargem Grande Paulista, além do município de São Paulo e do Governo do Estado de São Paulo3. Entendemos que a escolha desses cinco municípios era suficiente para cobrir as diferentes variáveis analisadas e para trazer evidências sobre desafios para implementação. Esta pesquisa não se propõe a generalizar os achados, de forma que a seleção da amostra não se baseou em critérios estatísticos, mas na variedade de contextos que pudessem evidenciar elementos importantes para compreender a implementação de políticas intersetoriais.

A partir da análise da estrutura de cada um dos municípios e de contato prévio com eles, foram selecionados os burocratas de médio escalão (BME) que estão envolvidos no Programa Bolsa Família dos municípios supracitados e que foram entrevistados. Ao todo, dos três níveis de governo, foram entrevistados 19 gestores, sendo 8 do Governo Federal (7 do Ministério de Desenvolvimento Social e 1 do Ministério da Saúde), 1 do governo estadual de São Paulo (da Secretaria de Desenvolvimento Social) e 10 dos governos municipais selecionados (1 da Prefeitura de São Paulo; 2 da Prefeitura de Caieiras; 2 da Prefeitura de BiritibaMirim; 4 da Prefeitura de Embu-Guaçu; 1 da Prefeitura de Vargem Grande Paulista). Selecionamos para entrevistar os coordenadores municipais responsáveis pelo Bolsa Família e que tivessem maior interação com o Governo Federal na implementação do programa. Estes são considerados burocratas de médio escalão pois não estão participando da formulação do programa, como parte do alto escalão, mas também não são identificados como aqueles que interagem diretamente com o públicoalvo - a burocracia do nível da rua; encontram-se, portanto, entre a formulação e a implementação direta (OLIVEIRA; ABRUCIO, 2018). A seleção desses atores se justifica por serem os pontos de intersecção das relações federativas e, ao mesmo tempo, por terem a responsabilidade de realizarem relações horizontais nas prefeituras, quando elas existem. Assim, mesmo sendo apenas 10 gestores municipais, os entrevistados eram os principais interlocutores a respeito do programa nos municípios selecionados e eram, portanto, os atores com as mais completas informações e claras percepções sobre sua implementação. Foram realizadas entrevistas presenciais com os gestores selecionados, nas quais foram levantados aspectos sobre a atuação desses gestores, as relações que estabelecem com outros atores e níveis de governo e sobre particularidades do PBF em seus contextos.

\footnotetext{
${ }^{3}$ Para maiores detalhes da metodologia de escolha dos casos, verificar o relatório final da pesquisa em http:// www.enap.gov.br/documents/586010/653300/170626_Caderno_50_De_qual_burocracia_proposta_digital. pdf/f3eba9f8-dddd-4eb4-a01b-af92102385f2/
} 


\subsection{A visão dos gestores sobre o PBF}

\section{A visão dos gestores federais do PBF}

A formação e trajetória dos gestores federais do PBF é bastante distinta daquela verificada no caso dos gestores municipais. No nível federal, a predominância de profissionais graduados, muitos deles gestores de carreiras de Estado, é clara. Dos entrevistados, alguns já possuíam experiência prévia na gestão pública, enquanto outros tinham experiências na iniciativa privada.

No tocante às responsabilidades, os gestores entrevistados assumem funções de gerência, como chefia e assessoria de gabinete; apoio aos estados e municípios, especialmente de capacitação de gestores nos níveis subnacionais; articulação com outros setores, dentro e fora do MDS, para a implementação do programa.

No que diz respeito às relações estabelecidas entre eles e outros agentes do programa, os gestores entrevistados estão muito mais próximos do alto escalão do que dos burocratas do nível da rua, não apenas internamente, dentro da estrutura hierárquica do MDS, como externamente, dentro de toda a estrutura, nacional e subnacional, envolvida no Programa Bolsa Família. Isso reforça achados prévios de pesquisas sobre o médio escalão federal que demonstram a proximidade maior deles com alto escalão do que com o nível de rua (CAVALCANTE; LOTTA, 2015). Como os próprios entrevistados apontaram, relacionam-se cotidianamente com o próprio Secretário da Senarc e sua equipe do gabinete; assessores, diretores e coordenadores gerais da Secretaria; secretarias e coordenadorias de outros ministérios, especialmente Ministério da Saúde (MS) e Ministério da Educação (MEC); Caixa Econômica Federal; coordenadores estaduais e municipais; secretários de Estado; dentre outros.

O que a análise das entrevistas dos gestores federais demonstra é o fato de que essa burocracia só pode ser compreendida em termos relacionais; e, sendo o posicionamento relacional considerado, o fato de que a mesma burocracia pode ser vista internamente como uma burocracia de médio escalão (no caso, dentro da Senarc), mas externamente, quando analisada a estrutura nacional de implementação do PBF, como uma burocracia de alto escalão, tendo em vista as funções que executa na sua ação cotidiana, a proximidade com o alto escalão da política, a distância em relação à ponta - no caso, a burocracia implementadora nos municípios. Não é possível generalizar esse achado para toda a BME, mas em estudos de caso anteriores foi possível ver situações bastante simulares em outras burocracias (PIRES, 2015; ABERS, 2015).

Quanto ao grau de autonomia dos gestores, vários afirmaram que têm uma situação de alta autonomia propositiva e baixa autonomia orçamentária. Somado 
a isso, algo que parece encontrar eco em análises teóricas (LOTTA; PIRES; OLIVEIRA, 2014 ) é o fato de que esses gestores se verem entre o técnico e o político. Nas palavras de uma das gestoras entrevistadas, "tenho um pé no técnico e um no político". Essa é uma das características centrais do burocrata de médio escalão, com implicações para a sua atuação cotidiana, mormente no que diz respeito à sua capacidade de diálogo com as duas "pontas" do processo de políticas públicas.

Outra questão central para essa burocracia implementadora é sua capacidade de articulação de diferentes setores. A gestora entrevistada do Ministério da Saúde (MS), Coordenadora-Geral de Alimentação e Nutrição, já atuou no nível municipal e em vários cargos da administração pública federal, sobretudo na área de segurança alimentar. A gestora demonstrou estabelecer interlocução constante com o MDS e com o MEC, ao mesmo tempo em que cuida do Bolsa Família internamente, dentro do MS, já que a saúde é parte importante do PBF. De acordo com a entrevistada, o papel da sua coordenadoria é de articuladora da rede de saúde e com assistência social e educação.

A gestora, assim como relatado por outros burocratas de médio escalão, disse ter alguma autonomia financeira, com recursos oriundos da Coordenação de Atenção Básica ("sem restrições para fazer oficinas, eventos"), e bastante autonomia para implementar inovações: tem liberdade para propor ações, sempre com base em diálogo com o MDS e com o MEC. Citou alguns exemplos de ideias aceitas e apoiadas pelo MDS: apoio da rede do Bolsa para combate à microcefalia e Zika; individualização do acompanhamento; integração com dados internos para identificar rapidamente a gestante etc.

Assim como os demais entrevistados, também relatou um duplo papel, tanto de empreendedora quanto de seguidora de ordens, sobretudo no processo de implementação do Bolsa Família e sua interação com a área da saúde. Papel similar tem sido encontrado em outras burocracias de médio escalão (ABERS, 2015) e pode ser enquadrado como um trabalho institucional, voltado a construir as próprias instituições e fazê-las operar - o que demanda tanto uma dimensão criativa como operacional. Em termos de conhecimentos, atitudes e habilidades, ressaltou a importância dos conhecimentos em gestão, da habilidade para ouvir e diagnosticar as necessidades dos indivíduos, e de uma atitude de liderança, proativa, capaz de articular com demais órgãos e instâncias, dentro e fora do MS. 


\section{A visão do gestor estadual do PBF}

Foram várias as tentativas de diálogo com a Secretaria Estadual de Desenvolvimento Social, mas apenas uma gestora aceitou dar uma entrevista. A gestora do Programa Bolsa Família do Estado de São Paulo foi entrevistada, mas a entrevista foi curta e pouco se falou sobre o programa, pois ela iniciou há pouco no cargo.

Sobre a atuação do estado, disse que o maior desafio é o de ampliar o cadastro para que mais famílias possam ser selecionadas para o PBF. Para isso, a Secretaria encontra-se numa fase de diagnóstico, buscando compreender por que os municípios não estão cumprindo suas metas. Uma das dificuldades decorre justamente da questão federativa e a falta de capacidade de diálogo entre governo estadual e governos municipais.

A comunicação ainda é falha, baseando-se sobretudo numa comunicação gabinete-gabinete, na qual a Secretaria Estadual comunica a Secretaria Municipal sobre o não cumprimento das metas de cobertura estabelecidas pelo Bolsa Família. No entanto, a gestora reconhece que essa estratégia (a comunicação entre gabinetes) não é eficiente e, por isso, a Secretaria Estadual dialoga diretamente com as diretorias regionais de assistência social (DRADS), da própria Secretaria Estadual. São 26 DRADS distribuídas pelo estado, mas estas contam com equipes reduzidas, de 6 a 8 funcionários em cada, para atender uma média de 25 municípios cada.

As DRADS são responsáveis pela capacitação dos municípios, mas a gestora enfatiza que esse papel é desempenhado pelo Governo Federal, que tem uma agenda anual de capacitação. Todavia, segundo a entrevistada, esta é falha, e o estado ainda não atua, embora devesse atuar, para ampliar a cobertura.

Por fim, quando questionada sobre o diálogo do Programa Bolsa Família com os demais programas do estado, afirmou que "o estado não quer concorrer com o Governo Federal". Nesse sentido, inclusive, fez a unificação dos cadastros, utilizando o Cadúnico. O programa estadual "Família Paulista", ainda um piloto, não é igual ao Bolsa Família, mas pretende ser mais abrangente, "integral". A gestora não deu mais resultados sobre o programa e não há descrição e/ou dados sobre o mesmo no site da Secretaria.

\section{A visão dos gestores municipais do PBF}

As entrevistas com gestores municipais do PBF demonstraram a diferença de universos entre as administrações públicas federal e municipais, sobretudo em termos de capacidade de articulação intersetorial e federativa. 


\section{a) Relação com os estados}

Muitos municípios relataram não possuir uma relação de parceria com o Governo do Estado de São Paulo. Conforme afirmaram, a relação é muito mais "burocrática" do que de cooperação. Alguns falaram que não possuem nenhuma relação com o governo estadual.

Os gestores entrevistados acreditam que o governo estadual poderia ter um plano de qualificação das gestões e da metrópole. Afirmam que os gestores estaduais não pensam em programas integrados de capacitação nem na cooperação entre municípios para a ação, fazendo planos de qualificação, por exemplo.

Dado que os estados não têm atendimento direto, os gestores municipais acreditam que poderiam assumir um papel mais estratégico, por exemplo, o de promotor de maior articulação horizontal entre municípios.

Relataram que o relacionamento com as Diretorias Regionais de Assistência e Desenvolvimento Social (DRADS) é mais indireto, por e-mail, do que direto e/ou de proximidade. Essas diretorias regionais se relacionam mais com a Secretaria de Desenvolvimento Social do que com o pessoal que cuida diretamente do Bolsa Família. De acordo com uma das gestoras do programa, "por ser um programa a nível federal, nunca vi o estado participar de nada a respeito do Bolsa Família".

Em geral, os municípios veem como ruim a participação do governo estadual no programa. Isso reforça a conclusão de outras pesquisas que têm analisado um constante esvaziamento dos governos estaduais em certas áreas de políticas públicas. Também reforça como alguns estados não têm assumido de fato um papel de coordenador dos municípios.

\section{Relação com o Governo Federal}

Já a relação com o Governo Federal é mais fácil, na visão da maior parte dos gestores, do que aquela com o governo estadual. O próprio programa impõe uma agenda que exige contato direto com o Governo Federal. No caso do Município de São Paulo, o gestor relatou a existência de um grupo de trabalho de gestores de metrópoles que conta com a participação do Governo Federal. Este é um espaço em que conseguem qualificar gestão, trocar experiência, propor ações e melhorias diretamente com o Governo Federal, "legislador" do programa.

O contato com o Governo Federal é direto, rápido, com ferramentas informais (telefone, e-mails, WhatsApp etc.). A equipe federal mostra-se disponível aos gestores municipais. Ademais, organizam encontros nacionais (Encontro do Cadúnico e das Metrópoles), o que facilita a comunicação e a troca de experiências. 
Em dois municípios houve relatos de maior dificuldade para acessar o Governo Federal. Nesses casos, a relação com o governo estadual, no entanto, é dita mais fácil, especialmente com as diretorias regionais (DRADS) - como nos casos de Biritiba-Mirim e Embu-Guaçu. As percepções dos gestores municipais sobre a atuação do Governo Federal reforçam achados anteriores sobre como as relações federativas têm operado no Brasil, por meio de relações diretas entre municípios e Governo Federal numa lógica de incentivos e induções via programas regulados nacionalmente e implementados localmente (ARRETCHE, 2012). Em alguns programas do Governo Federal, como é o caso do Programa Minha Casa Minha Vida, o planejamento local é fortemente influenciado pelos interesses da iniciativa privada - no caso, das empreiteiras responsáveis pelo empreendimento (MourA, 2014). Ao contrário, o caso do PBF se mostra bem-sucedido em termos de investimento das burocracias do Governo Federal na construção de capacidades locais.

\section{b) Intersetorialidade}

Em geral, os gestores municipais relataram como tranquila a relação com gestores de outras secretarias ou programas governamentais. Em especial, mencionam a relação com as Secretarias de Saúde e de Educação, constante por conta das condicionalidades. Relacionam-se também com psicólogos e assistentes sociais dos Centros de Referência de Assistência Social (CRAS) e Centros de Referência Especializada em Assistência Social (CREAS).

A relação entre as áreas de políticas públicas dentro do município (cooperação intramunicipal) é mais fácil do que aquela com órgãos governamentais de outros níveis federativos (cooperação intergovernamental). Conforme explicitado anteriormente, nem sempre a relação com o Governo Federal e/ou estadual é tranquila e rápida. Isso é um reflexo da dificuldade em se implementar localmente um programa desenhado pelo Governo Federal e que conta com participação (ainda que pequena) dos governos estaduais.

\section{d) Gestão das regras}

Um dos aspectos apresentados pelo gestor do município de São Paulo é o fato de o programa ser desenhado centralmente, mas com implementação local. Afirmou que seria interessante se o programa tivesse vários desenhos e formatos, condizentes com as distintas realidades locais. De acordo com o mesmo, "não dá para ser um programa único, chapado". A uniformização do programa não é condizente com a heterogeneidade do federalismo brasileiro. 
Um dos papéis dos gestores municipais é, inclusive, o de "traduzir" as normas federais em normas que possam ser implementadas no nível local. Nas palavras do gestor:

Não dá pra pegar a regra que chega do Governo Federal e repassar. Eu tenho que pegar, interpretar, entender nossa realidade e transformar a regra para o que nós temos e podemos.

Isso reforça uma operação do federalismo brasileiro, em que há regras gerais construídas nacionalmente a serem implementadas localmente. No caso do Município de São Paulo, em que o contexto é muito diverso das demais localidades, as regras federais aparentemente não se enquadram à realidade local. Mas é interessante notar que essa questão não apareceu nos demais municípios entrevistados. Uma das hipóteses para esse achado pode estar relacionada ao fato de que as regras gerais são mais adequadas a municípios de porte menor ou não metrópoles. Mas é uma questão a ser melhor investigada em outros estudos.

\subsection{Percepções da burocracia implementadora de diferentes níveis de governo}

Os entrevistados, de maneira geral, ressaltaram a necessidade de um contato mais próximo entre os municípios e os demais entes federados - em especial o estado. Conforme o Decreto no 5.209, de 17 de setembro de 2004, em seu art. 14, cabe aos estados:

I - constituir coordenação composta por representantes das suas áreas de saúde, educação, assistência social e segurança alimentar, quando existentes, responsável pelas ações do Programa Bolsa Família, no âmbito estadual;

II - promover ações que viabilizem a gestão intersetorial, na esfera estadual;

III - promover ações de sensibilização e articulação com os gestores municipais;

IV - disponibilizar apoio técnico-institucional aos Municípios;

$\mathrm{V}$ - disponibilizar serviços e estruturas institucionais, da área da assistência social, da educação e da saúde, na esfera estadual;

VI - apoiar e estimular o cadastramento pelos Municípios;

VII - estimular os Municípios para o estabelecimento de parcerias com órgãos e instituições municipais, estaduais e federais, governamentais e nãogovernamentais, para oferta dos programas sociais complementares; e

VIII - promover, em articulação com a União e os Municípios, o acompanhamento do cumprimento das condicionalidades.

Constatou-se que, na percepção dos gestores municipais entrevistados, o governo estadual não desempenha suas competências conforme estabelecido em 
lei. Segundo os entrevistados, os contatos com o estado são pontuais e tratam, na esmagadora maioria das vezes, das capacitações aos profissionais e, de acordo com um dos profissionais entrevistados, tais capacitações só ocorrem quando há exigência do Governo Federal. A contratação de mais funcionários, por parte do governo estadual, é vital para o cumprimento de suas atribuições e para auxiliar os municípios na gestão adequada do Programa, pois, em mais de uma ocasião, ouviu-se que o estado não era atuante por não possuir profissionais que pudessem se dedicar ao Programa Bolsa Família e suas exigências. Assim como o estado, os municípios enfrentam desafios quanto ao quadro de funcionários.

Em municípios de pequeno porte, como Vargem Grande Paulista, a gestora do Bolsa exerce competências que extrapolam aquelas inerentes à sua função. $O$ coordenador de São Paulo pontua, como supracitado, que a definição nacional de uma equipe mínima de funcionários para a operacionalização do programa no âmbito local implicaria em grandes avanços na qualidade da gestão do programa. Mostra-se igualmente problemática para a gestão a falta de espaços para a descentralização das ações do programa. A construção de mais equipamentos, como o CRAS e o CREAS, são reinvindicações dos gestores do programa para aferir maior qualidade na gestão e no atendimento das famílias beneficiárias.

Questão importante diz respeito ao processo de indicação do gestor municipal do Programa Bolsa Família. A livre nomeação por parte do chefe do Executivo municipal implica, por vezes, a indicação de pessoas que não são familiarizadas com o tema. Em um dos municípios estudados, a cunhada do prefeito é a gestora municipal e delega a outros profissionais suas funções. A indicação da secretária da pasta responsável pelo programa, como recomenda o Informe 01 do MDS, traz implicações para sua atuação, pois os profissionais possuem dupla função e, com isso, delegam aquelas relativas especificamente ao PBF aos coordenadores técnicos.

Além das dificuldades enfrentadas pela gestão local por falta de espaços, de funcionários ou pelo modo pelo qual o gestor é indicado, os recursos transferidos pelo IGD também se mostram problemáticos. Com exceção de São Paulo, que recebe um montante vultoso de transferências, os demais municípios recebem poucos recursos e apresentam dificuldades em gastá-los. Um exemplo dessa baixa transferência é o Município de Embu-Guaçu, no qual a gestora conta que foram necessários quatro meses somados de transferência para a compra de um automóvel, o qual é vital para a locomoção até as famílias beneficiárias. Sobre as dificuldades na execução desses recursos, percebe-se que as capacidades institucionais locais são determinantes. Nos municípios que possuíam as maiores quantidades de recursos disponíveis em conta em 2015 (Vargem Grande Paulista, com R\$ 278.008,27; e Caieiras, com R\$ 307.371,63), encontravam-se dois 
desafios diferentes: no primeiro, o entendimento sobre o gasto do IGD por parte da instância de controle social (ICS) e das questões administrativas da prefeitura como licitações e contratos - eram fatores que impediam a execução dos recursos. A gestora comenta que teve que realizar inúmeras conversas a respeito de como os recursos do IGD poderiam ser gastos e contar com o apoio do Executivo municipal para conscientizar os membros da ICS e do setor de contabilidade da prefeitura. No segundo município, a execução dos recursos do IGD era impossibilitada pela falta de entendimento entre a gestora municipal e a Secretária de Assistência Social. Esse desafio é potencializado devido ao PBF estar alocado na Secretaria de Educação. Portanto, o Governo Federal deve-se atentar às transferências via IGD no que tange à quantidade de recursos e à sua gestão.

Deve-se ter atenção, por parte do Governo Federal e estadual, para em qual secretaria o Programa Bolsa Família está alocado. Segundo dados da Munic 2013, 75\% dos municípios brasileiros possuíam órgãos exclusivos para tratar da política de assistência social. Os demais municípios apresentavam os órgãos que tratam da política de assistência social associados a outros órgãos. Portanto, 25\% dos municípios brasileiros não possuem estrutura exclusiva para a política de assistência social e, conforme levantado nas entrevistas (em especial no município de Caieiras), quando o Programa Bolsa Família não está em um órgão exclusivo de assistência social, desafios são enfrentados pela gestão do programa. Segundo a Coordenadora Técnica de Caieiras "até ano passado não existia o Bolsa para a Secretaria de Assistência Social". Como denota Bichir (2011, p. 140), "em um contexto no qual o governo federal estimula a integração crescente dos programas de transferência de renda no interior da assistência, faz cada vez mais sentido contar com uma estrutura organizacional própria para a política". Desse modo, cabe aos Governos Federal e estadual incentivarem a criação de órgãos exclusivos no âmbito local.

Observa-se, ainda, que o maior gap de competência apresentado pelos municípios selecionados diz respeito à articulação com outros órgãos das três esferas e com entidades não governamentais para a implementação de programas complementares. Como supracitado, o conceito de pobreza multidimensional é basilar para o Programa Bolsa Família e necessita da atuação dos gestores para ser efetivado. Os Governos Federal e estadual devem desenvolver estratégias que visem fortalecer a atuação dos órgãos gestores do programa para que esses atuem articulados com diferentes atores nas mais diversas frentes de combate à pobreza.

Outro ponto interessante de atuação para o Governo Federal e estadual é no fomento à articulação regional para o fortalecimento da gestão do Programa Bolsa Família nos municípios. Institucionalizar espaços e mecanismos de cooperação intermunicipais pode ser um importante passo para suprir inúmeros desafios que 
os municípios apresentam, uma vez que a troca de experiências e o intercâmbio de informações facilita a resolução de problemas comuns.

Por fim, cabe ressaltar uma área de atuação aos Governos Federal e estadual que diz respeito especificamente ao Município de São Paulo: o planejamento metropolitano da gestão do Programa Bolsa Família. O coordenador argumenta que se deve planejar a gestão do Bolsa levando em conta as especificidades locais, as quais não são observadas nas regras únicas utilizadas pelo Governo Federal. Para o coordenador, além de rever essas regras, o maior envolvimento do governo estadual no planejamento das ações do programa é essencial para dar um salto de qualidade na gestão.

\subsection{Competências da burocracia implementadora do Bolsa Família}

Por fim, as entrevistas realizadas e a análise da literatura permitiram identificar um conjunto de desafios a serem enfrentados pelos entes governamentais para efetivação do PBF. Esses desafios requerem dos gestores competências específicas para conseguirem lidar com o cotidiano do programa e gerar resultados positivos. Essas competências estão relacionadas tanto às capacidades de articulação intersetorial, como à construção de relações federativas e desenvolvimento de capacidades técnicas e políticas. Como os casos demonstram, as competências devem ser diferentes considerando-se o nível federativo analisado. A seguir, apontamos algumas dessas competências, mapeadas tanto pela literatura como pelos estudos de caso realizados, e que apontam para qual o perfil requerido de burocracia para dar conta dos desafios identificados na implementação do PBF:

a. Competências para articulação: a articulação vertical e horizontal, base do PBF, requer dos gestores uma ampla capacidade de se articularem com diferentes conhecimentos, lógicas e modus operandi (SILVA, 2013).

b. Politização: o estudo permite perceber que o desenvolvimento do PBF demanda capacidades políticas da burocracia por ele responsável. Essas capacidades relacionam-se com a possibilidade de se articularem com atores da política, mas também com tomarem decisões políticas com relação ao programa (SILVA, 2013).

c. Alta qualificação: as pesquisas de Pizzolato (2014) apontam uma forte correlação entre a alta qualificação educacional dos gestores do PBF e os resultados positivos do programa.

d. Criatividade: parte do sucesso do PBF vem da criatividade e experimentalismo dos gestores do programa em nível federal (SILVA, 2013; OLIVEIRA; LOTTA, 2015). A criatividade aparece como uma competência necessária para a inovação, que, por sua vez, é pressuposto para os bons resultados do programa. 
e. Capacidade de gerar institucionalização: parte do sucesso do programa é resultado da dedicação dos gestores em construírem processos institucionalizados para garantir tanto sua permanência como sua proteção e memória institucional. Isso requer dos gestores conhecimentos sobre legislação, processo legislativo, desenho de processos etc. (SILVA, 2013; OLIVEIRA; LOTTA, 2015).

No caso mais específico dos municípios, algumas competências requeridas que puderam ser identificadas foram:

a. Competências para promover processos participativos: como aponta Coutinho (2013), o PBF tem como base a lógica da democratização. Para tanto, requer que os gestores saibam desenvolver práticas participativas que contemplem a sociedade na tomada de decisão.

b. Competências para promover integração com assistência social: um dos desafios para o futuro do PBF tem a ver com a integração crescente entre Bolsa Família e Suas. Para tanto, demandam-se competências dos gestores municipais no sentido de conseguirem realizar ações articuladas olhando para a assistência social de forma integrada e abrangente.

Essas competências, relacionadas com os desafios da implementação intersetorial e intergovernamental, captadas nas entrevistas com os diversos gestores, permitem identificar alguns dos elementos que deveriam ser aprimorados em termos de formação da burocracia para melhorar a gestão e implementação de uma política com tais especificidades como o PBF.

\section{Considerações finais}

Partimos, neste artigo, da lacuna existente na literatura a respeito dos burocratas de médio escalão estaduais e municipais, especialmente no âmbito do Programa Bolsa Família. Os estudos publicados têm por objetivo a análise dos impactos do programa, mas não empreendem a análise da atuação dos burocratas na gestão do PBF. Esta, no entanto, é parte essencial para compreendermos o processo de implementação do PBF. Segundo Bichir (2011), que analisou o processo de implementação do PBF em São Paulo e Salvador,

o processo de implementação do PBF é afetado não só por seu desenho institucional, definido no plano federal, mas também pelas diferentes capacidades institucionais disponíveis no plano local - recursos humanos, capacidade de gestão e articulação entre diversos serviços e políticas, infraestrutura disponível, entre outros aspectos [...] (BICHIR, 2011, p. 9). 
Tal afirmação corrobora a importância de se estudar tais capacidades institucionais disponíveis no plano local e, visando minorar essa lacuna, analisamos a burocracia municipal, a partir da escolha de municípios de diferentes perfis, buscando compreender como os gestores, em especial os municipais, percebem os desafios da implementação de políticas intersetoriais e federativas como o Bolsa Família.

No que tange o Governo Federal, trabalhos como o de Oliveira e Lotta (2015) e de Silva (2013) argumentam que o sucesso da burocracia de médio escalão do PBF ocorreu por meio da "separação entre critérios técnicos, sobretudo a policy expertise, e político-partidários" (OLIVEIRA; LOTTA, 2015, p. 116). Em suma, o êxito dos BME federais se deu por meio da utilização de empoderamento da burocracia,

(...) o que fez emergir o protagonismo de uma burocracia de nível médio (ou intermediário), com alta qualificação técnica e com importantes capacidades de articulação (formal ou informal), seja com outros burocratas, seja com o corpo político (SILVA, 2013, p. 328).

No entanto, sabe-se que as capacidades institucionais federais não são iguais ou, muitas vezes, nem mesmo próximas das capacidades locais. Pizolatto (2014) reforça esse argumento ao constatar a diferença existente entre as burocracias dos entes federados, "com destaque para a pior condição dos entes municipais, os quais possuem grandes atribuições advindas do processo de descentralização" (p. 68). Essa condição é ressaltada por Coelho et al. (2010), na medida em que as autoras destacam a dificuldade dos profissionais em participarem de reuniões das equipes dos demais setores, muitas vezes em função do acúmulo de tarefas burocráticas, da ausência de estímulo e de planejamento no processo de trabalho.

Além das desigualdades entre os entes federados, há de se ater às desigualdades existentes entre os diferentes municípios brasileiros. A análise da base de dados da Pesquisa de Informações Básicas Municipais (MUNIC) realizada por Bichir (2011) evidencia as desigualdades entre as capacidades institucionais, em que o tamanho do município faz muita diferença nas competências de gestão do Programa Bolsa Família.

Além das desigualdades locais e das distintas capacidades burocráticas dos níveis de governo, um conjunto de questões apareceu como importante para se enfrentar o desafio da implementação das políticas públicas com as características aqui analisadas.

Em primeiro lugar, os gestores federais e municipais apontam um exercício constante de construção da intersetorialidade na operação do programa. Ela se dá diretamente com a gestão das condicionalidades (educação e saúde), mas também aparece na gestão com outros setores federais ou municipais para construção de 
outras estratégias articuladas. A intersetorialidade, no entanto, aparece no discurso como uma ação constante a ser perseguida e que depende de uma atuação em torno da articulação e negociação com outros atores, voltada inclusive à construção (ou disseminação) das narrativas sobre o PBF. Coloca-se também como uma dimensão importante para exercício da intersetorialidade a capacidade de conectar vários temas diferentes de gestão e fazer tradução entre eles.

Em segundo lugar, gestores federais e municipais apontaram que o Governo Federal deveria desenvolver mecanismos melhores para compreensão da linguagem dos diferentes públicos e atores existentes nos municípios. É constante uma crítica (e idealização) de que a política melhoraria se os gestores federais conseguissem compreender melhor o que acontece na ponta e incorporassem esses aprendizados ao (re)desenho da política e à customização da mesma.

Por fim, os gestores municipais colocaram a questão da necessidade de maior adequação da política federal às distintas realidades locais, "customizando" a política e suas regras. No entanto, como argumentam, isso demanda conhecimentos acerca das especificidades locais a serem captadas pelos atores federais para proposição de ações específicas. Esse talvez seja um objetivo a ser atingido, mas apenas depois de se ter alcançado a intersetorialidade e a cooperação federativa esperadas.

Enfim, os desafios apontados pelos gestores entrevistados expõem a complexidade dos processos de implementação de políticas que demandam articulação horizontal (intersetorial) e vertical (intergovernamental), como é o caso do Bolsa Família. Como se sabe, são muitas as políticas públicas com esse perfil e com as quais os gestores lidam cotidianamente. Compreender quais são os desafios para sua implementação parece-nos essencial para o aprimoramento da gestão pública e, portanto, do resultado alcançado pelas administrações públicas na sua ação de prover serviços públicos de qualidade.

\section{Referências bibliográficas}

ABERS, Rebecca. O encontro entre o combate à pobreza e o ambientalismo: os burocratas do Bolsa Verde". In: CAVALCANTE, P. L.; LOTTA, G. Burocracia de médio escalão: perfil, trajetória e atuação. Brasília: Enap, 2015.

ALMEIDA, Maria Hermínia T. Recentralizando a Federação? Revista de Sociologia e Política, Curitiba, n. 24, p. 29-40, jun. 2005.

ANDRADE, Guilherme Parra de. "Burocracia de Médio Escalão: uma análise da atuação no nível municipal a partir da abordagem dos arranjos institucionais". Dissertação de mestrado apresentada ao Programa de Pós-Graduação em Políticas Públicas da UFABC. São Bernardo do Campo, SP, 2018.

ARRETCHe, Marta. Democracia, federalismo e centralização no Brasil. 1. ed. Rio de 
Janeiro: Fundação Getulio Vargas/Fiocruz, 2012. Vol. 1.

BICHIR, Renata Mirandola. Mecanismos federais de coordenação de políticas sociais e capacidades institucionais locais. 2011. Tese de Doutorado, Universidade Federal do Rio de Janeiro, Rio de Janeiro, 2011.

Bouckaert, G.; Peters, G.; Verhoest, K. The coordination of public sector organizations: shifting patterns of public management. London: Palgrave MacMillan, 2010.

BRESSER-PeReIRA, Luiz Carlos. Burocracia pública e classes dirigentes no Brasil. Revista de Sociologia e Política, n. 28, p. 9-30, jun. 2007.

CAvalcante, Pedro L. Programa Bolsa Família: descentralização, centralização ou gestão em redes? Trabalho apresentado no II Congresso Consad de Gestão Pública, 2009.

CAVALCANTE, Pedro L.; LOTTA, Gabriela. Burocracia de médio escalão: perfil, trajetória e atuação. Brasília: Enap, 2015.

COELHO, Vera Schattan; FERRAZ, Alexandre; FANTI, Fabiola; Ribeiro, Meire de Paula. Mobilização e participação: Um jogo de Soma zero? Um estudo sobre as dinâmicas de conselhos de saúde da cidade de São Paulo. Novos Estudos CEBRAP (Impresso), v. 86, p. 120-139, 2010.

COUTINHO, Diogo. Decentralization and coordination in social law and policy: the Bolsa Família Program. In: TRUBEK, David et al. (Ed.). Law and the new developmental state: the Brazilian experience in Latin American context. Cambridge University Press, 2013.

CUNILL GRAU, Nuria. La intersectorialidad en el gobierno y gestión de la política social. In: Congreso InTERnacional Del CLAD, 9. Chile: Clad, 2005.

DiReIto, Denise C.; KogA, Natália M.; Lícıo, Elaine C.; ChAVES, Jeniffer C. The single registry as a tool for the coordination of social policies. Working Paper n. 145, july 2016, International Policy Centre for Inclusive Grouth, 2016.

GodinHo, Letícia. Dilemas de uma burocracia de médio escalão no contexto de implementação de uma política frouxamente articulada. In: CAVALCANTE, P. L.; LOTTA, G. Burocracia de médio escalão: perfil, trajetória e atuação. Brasília: Enap, 2015. GouVÊA, G. P. Burocracia e elites burocráticas no Brasil. São Paulo: Paulicéia, 1994. HUISING, R.; SILBEY, S. S., Governing the gap: forging safe science through relational regulation. Regulation \& Governance, v. 5, p. 14-42, 2011.

INOJOSA, R. M. Intersetorialidade e um novo paradigma organizacional. Revista de Administração Pública, v. 32, n. 2, p. 35-48, 1998.

Licio, Elaine; Mesquita, C.; CuRrarelo, C.R. Desafios para a coordenação intergovernamental do Programa Bolsa Família. Revista de Administração de Empresas, eRAE, São Paulo, v. 51, n. 5, set./out. 2011.

LotTA, Gabriela S.; FAVARETTo, Arilson. Desafios da integração nos novos arranjos institucionais de políticas públicas no Brasil. Revista de Sociologia e Política, v. 24, n. 57, p. 49-65, mar. 2016.

LOTTA, Gabriela; PIRES, Roberto Rocha C.; OLIVEIRA, Vanessa Elias. Burocratas de 
médio escalão: novos olhares sobre velhos atores da produção de políticas públicas. Revista do Serviço Público, v. 65, n. 4, 2014.

LOUREIRO, Maria Rita; ABRUCIO, Fernando L. Política e burocracia no presidencialismo brasileiro: o papel do Ministério da Fazenda no primeiro Governo Fernando Henrique Cardoso. Revista Brasileira de Ciências Sociais, v. 14, n. 41, out. 1999.

LoUReIRo, Maria Rita; ABrucio, Fernando L.; RoSA, C. A. Radiografia da alta burocracia federal brasileira: o caso do Ministério da Fazenda. Revista do Serviço Público, v. 49, n. 4, out.-dez. 1998.

MourA, Jéssica. O Programa Minha Casa Minha Vida na região metropolitana de Natal: uma análise espacial dos padrões de segregação e desterritorialização. Urbe - Revista Brasileira de Gestão Urbana, v. 6, n. 3, p. 339-359, set./dez. 2014.

OLIVEIRA, Breynner R. A implementação do Programa Bolsa Família sob a perspectiva da condicionalidade educacional: uma análise a partir dos agentes públicos de base. Revista do Serviço Público, Brasília, v. 65, n. 4, out./dez. 2014.

OLIVEIRA, Vanessa Elias; LOTTA, Gabriela. Qualificando a recentralização: repasses e relações intergovernamentais no Brasil. Trabalho apresentado no 38을 Encontro da Anpocs, Caxambu, 2014.

OlIVEIRA, Vanessa Elias Instituições, burocracia e produção de políticas públicas: o caso da política estadual de saúde. Paper preparado para o 33을 Encontro Anual da Anpocs, mimeo, 2009.

OLIVEIRA, Vanessa Elias; ABRUcio, Fernando Luiz. Burocracia de médio escalão e diretores de escola: um novo olhar sobre o conceito. In: PIRES, R.; LOTTA, G.; OLIVEIRA, V.E. Burocracia e políticas públicas no Brasil: intersecções analíticas. Brasília: Ipea, Enap, 2018.

OlIVEIRA, Vanessa Elias; LOTTA, Gabriela. Implementando uma inovação: a burocracia de médio escalão do Programa Bolsa Família. In: CAVALCANTE, P. L.; LOTTA, G. Burocracia de médio escalão: perfil, trajetória e atuação. Brasília: Enap, 2015.

OLIVIERI, Cecília. Política, burocracia e redes sociais: as nomeações para o alto escalão do Banco Central do Brasil. Revista de Sociologia e Política, n. 29, nov. 2007. PIRES, Roberto. Por dentro do PAC: arranjos, dinâmicas e instrumentos na perspectiva dos seus operadores. In: CAVALCANTE, P. L.; LOTTA, G. Burocracia de médio escalão: perfil, trajetória e atuação. Brasília: Enap, 2015.

PIRES, R.; LOtTA, G.; OliveIRA, V.E. Burocracia e políticas públicas no Brasil: intersecções analíticas. Brasília: Ipea, Enap, 2018.

Pizzolato, B. Desempenho dos municípios na gestão do Programa Bolsa Família: o impacto das características da burocracia local. Dissertação de mestrado apresentada na Escola de Administração de Empresas da FGV/SP, 2014.

PüLzL, H.; TREIB, O. Implementing public policy. Handbook of Public Policy Analysis: Theory, Politics, and Methods, v. 125, p. 89--07, 2007.

SCHNEIDER, Ben R. Burocracia Pública e Política Industrial no Brasil. São Paulo: Editora Sumaré, 1994.

SILVA, Lucas Ambrózio. Burocracia de médio escalão da Secretaria da Receita Federal 
do Brasil: burocracia clássica e insulamento seletivo. In: CAVALCANTE, P. L.; LOTTA, G. Burocracia de médio escalão: perfil, trajetória e atuação. Brasília: Enap, 2015.

SILVA, Lucas Ambrózio. Mecanismos da construção federal da intersetorialidade no Programa Bolsa Família: o papel das burocracias. Revista do Serviço Público, Brasília, v. 64, n. 3, p. 309-326, jul./set. 2013.

YANOW, Dvora. The communication of policy meanings: implementation as interpretation and text. Policy Sciences, v. 26, n. 1, p. 41-61, 1993. JSTOR, JSTOR, www.jstor.org/stable/4532276.

\section{Vanessa Elias de Oliveira}

Universidade Federal do ABC (UFABC). Mestre em Saúde coletiva pela Faculdade de Ciências Médicas da Santa Casa de São Paulo. Mestre e Doutora em Ciência Política pela Universidade de São Paulo. Professora e Pesquisadora da Universidade Federal do ABC. Coordenadora da Pós-Graduação em Políticas Públicas da Universidade Federal do ABC.

\section{Gabriela Spanghero Lotta}

Fundação Getulio Vargas (FGV). Mestre em Administração Pública pela Fundação Getúlio Vargas. Doutora em Ciência Política pela Universidade de São Paulo. Pesquisadora do Centro Brasileiro de Análise e Planejamento. Professora e pesquisadora de Administração Pública e Governo da Fundação Getúlio Vargas. Professora da Escola Nacional de Administração Pública.

\section{Matheus Nunes}

Graduado em Ciências e Humanidades pela Universidade Federal do ABC. Graduado em Políticas Públicas pela Universidade Federal do ABC. 